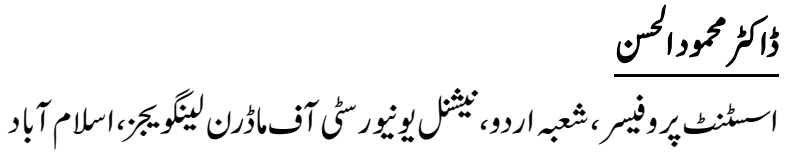

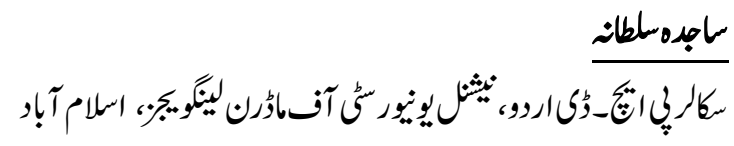

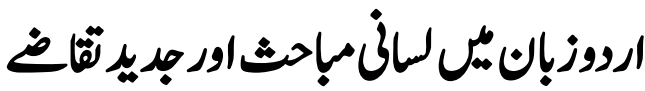

\section{Dr. Mahmood-ul-Hassan}

Assistant Professor, Urdu Department, NUML, Islamabad

Sajida Sultana

Scholar Ph.D Urdu, NUML, Islamabad

\section{Linguistic Discussions and Modern Requirements in \\ Urdu Language}

Basic Linguistic debates in Urdu Language are found in form of books, grammar books and dictionaries. These books were written in view of teaching requirements. Its writers and compilers were from local scholars and European orientalists. Overviewing new linguistic discussions in this article, it has been deduced that least work was done in research and no benefit has been taken from new linguistic techniques.

Keywords: Basic, Debates, Grammar, Books, Orientalists, Techniques.

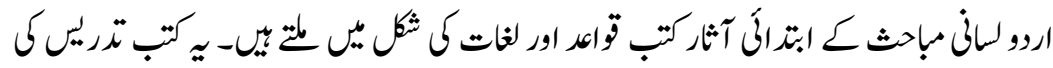

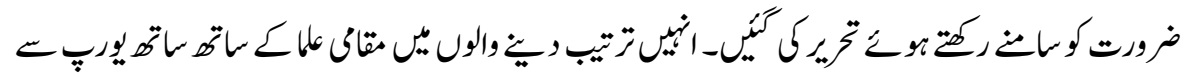

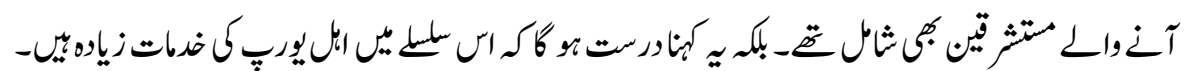

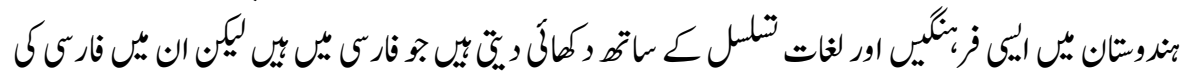

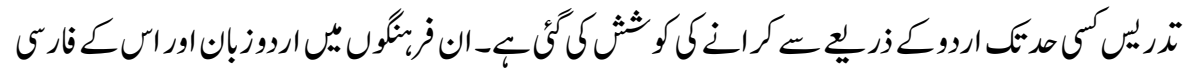

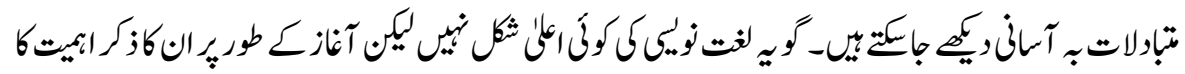

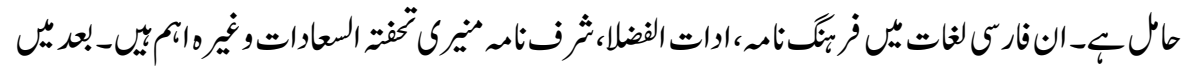




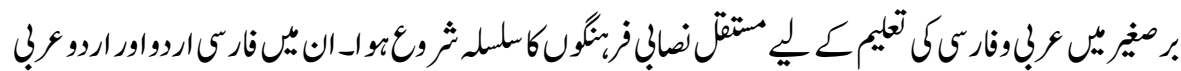

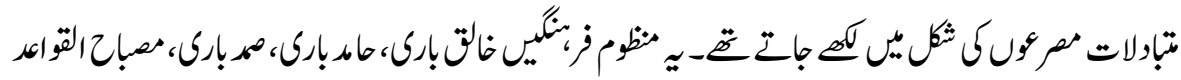

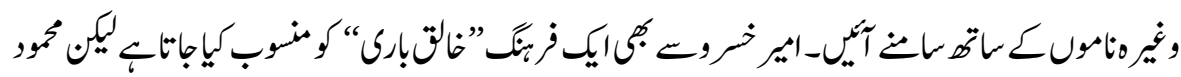

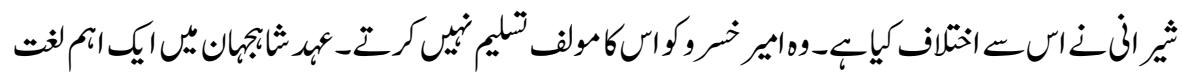

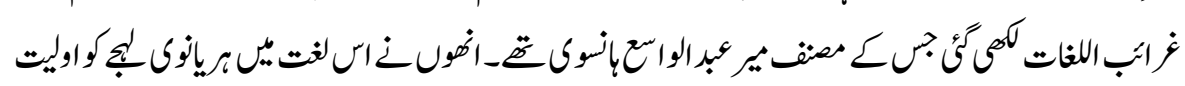

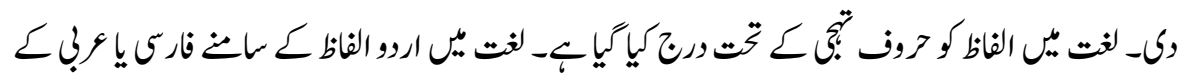

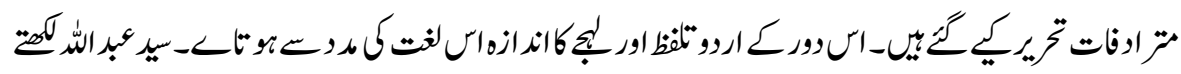

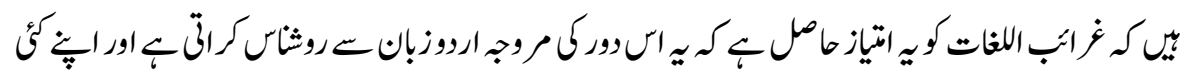

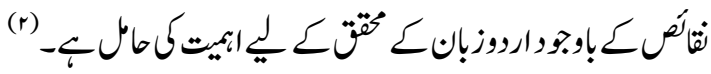

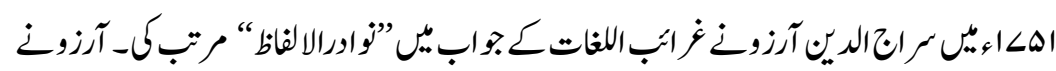

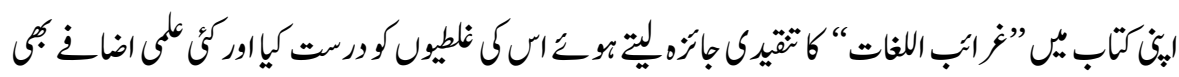

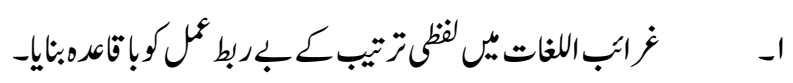

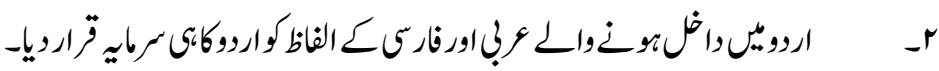
rـ

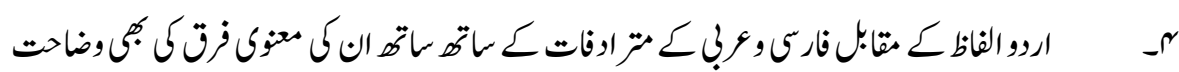

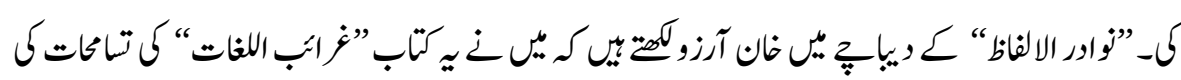
(r)

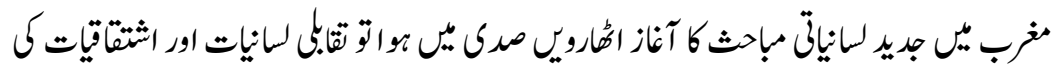

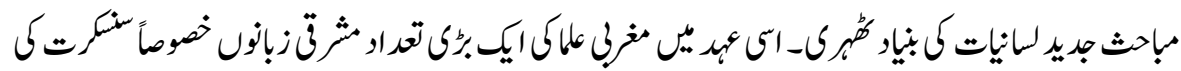

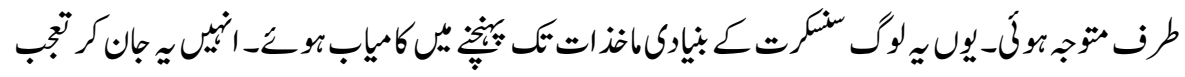

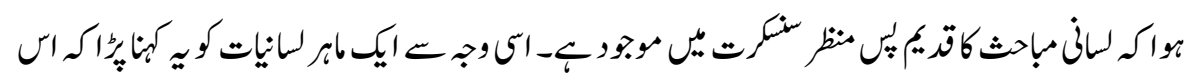




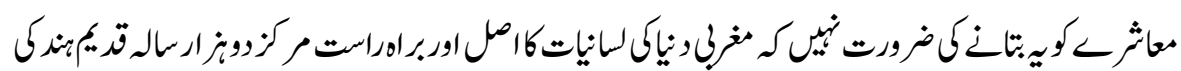

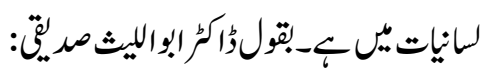

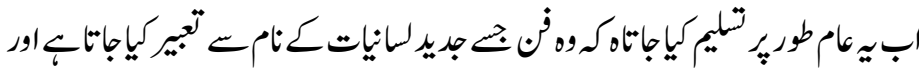

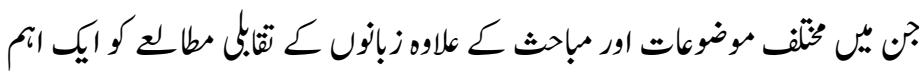

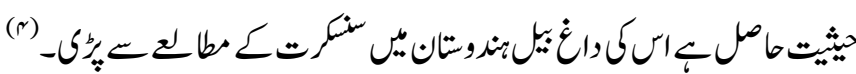

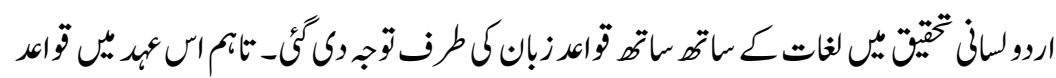

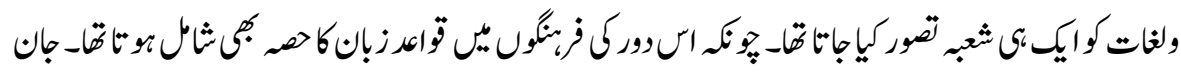

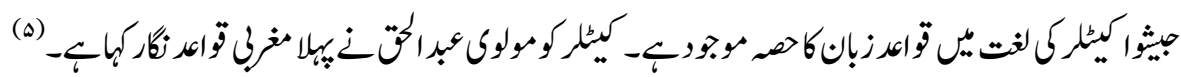

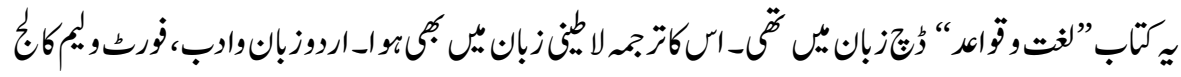

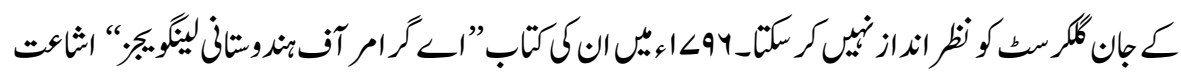

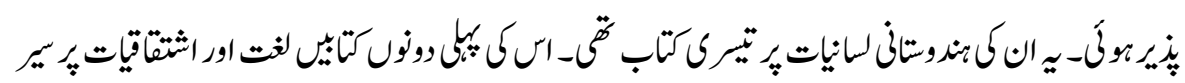

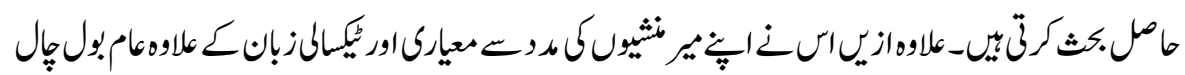

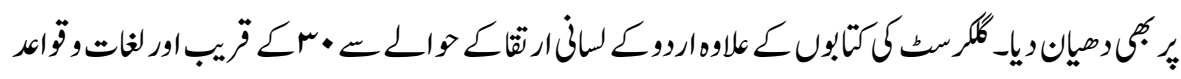

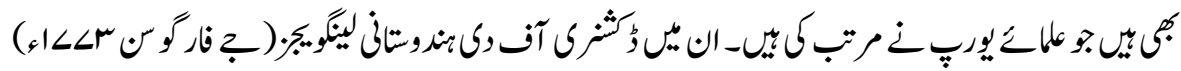

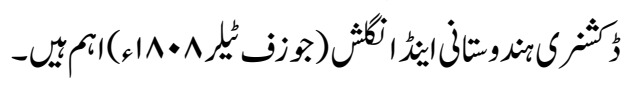

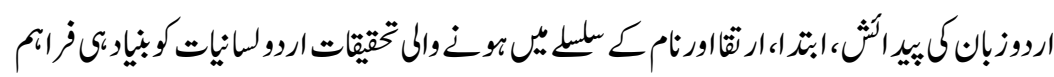

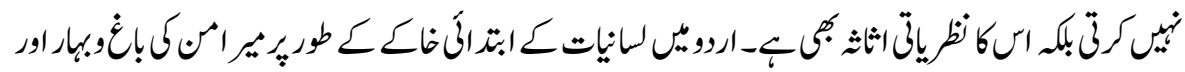

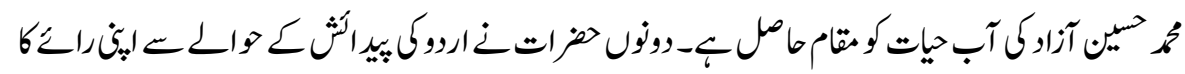

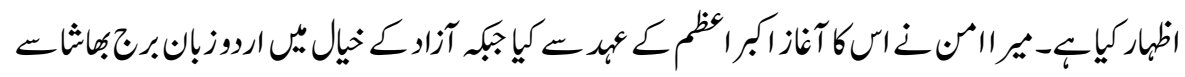

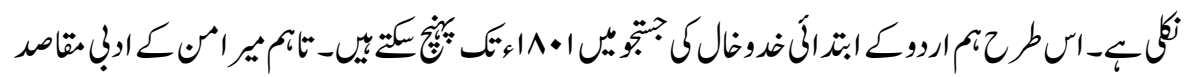

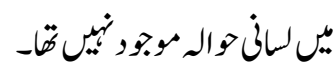

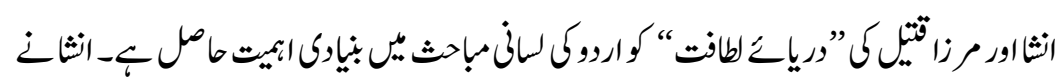

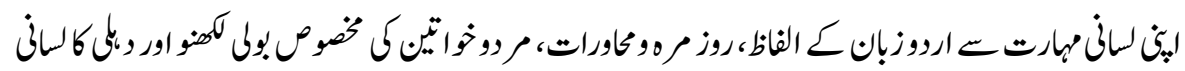




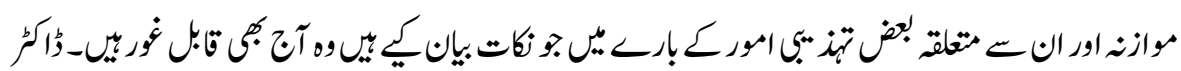

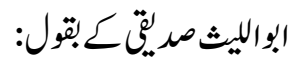

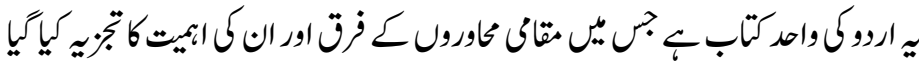

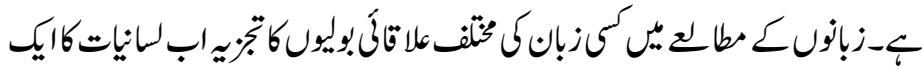

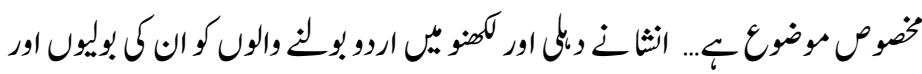

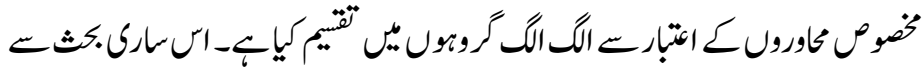

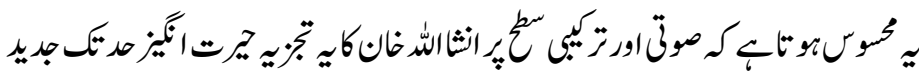

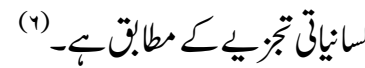

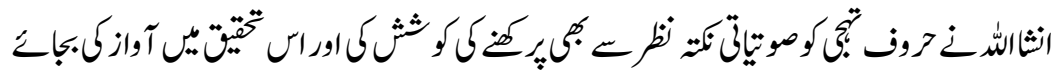

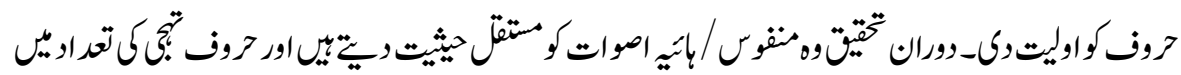

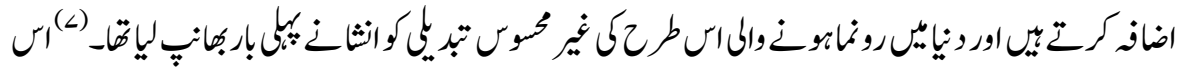

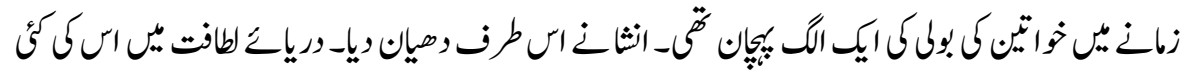

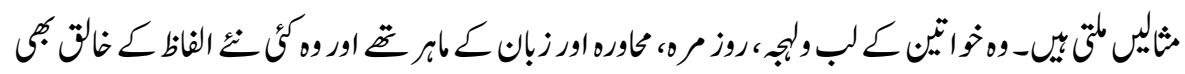

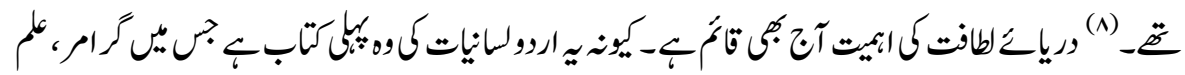

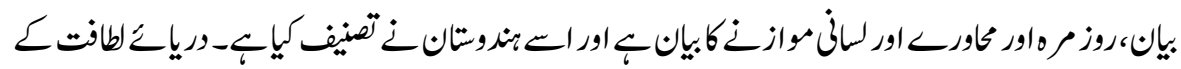

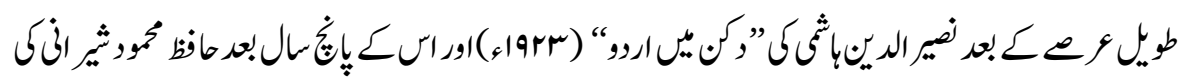

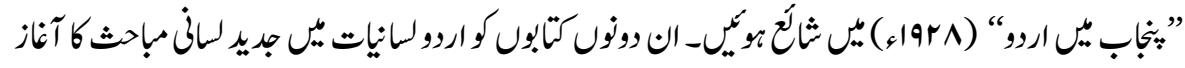

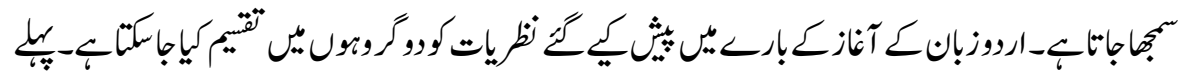

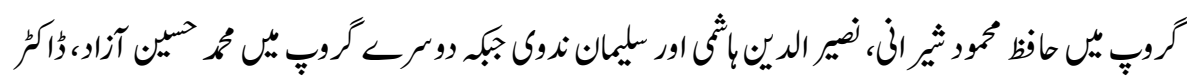

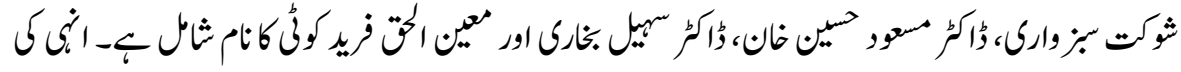

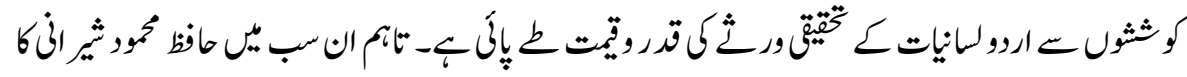

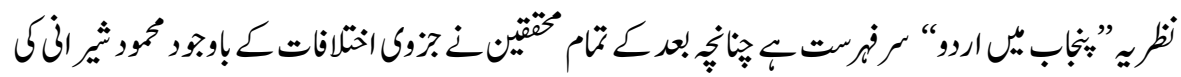

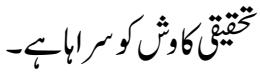




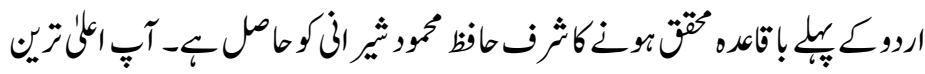

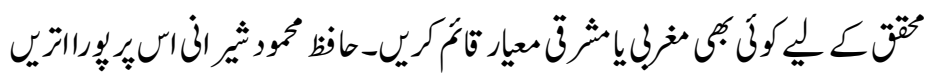

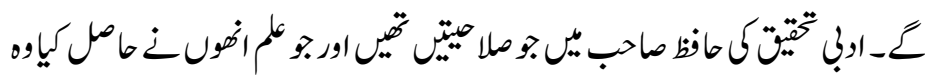

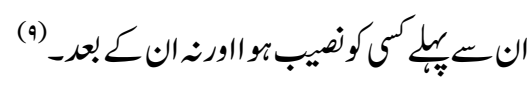

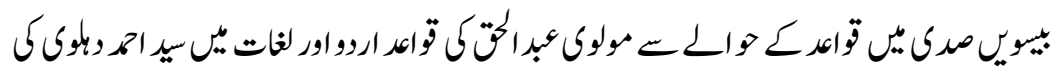

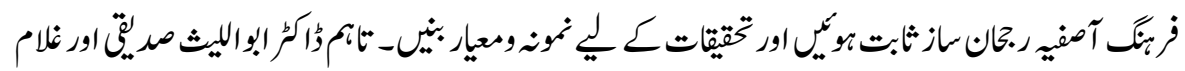

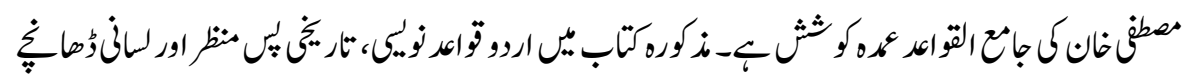

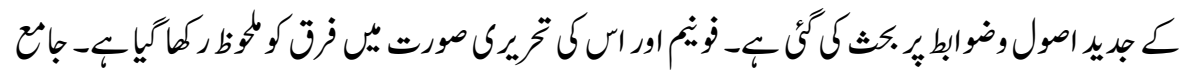

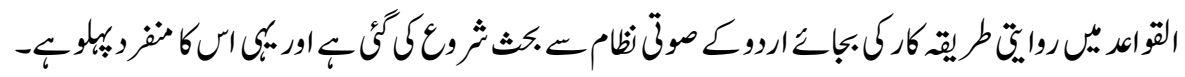

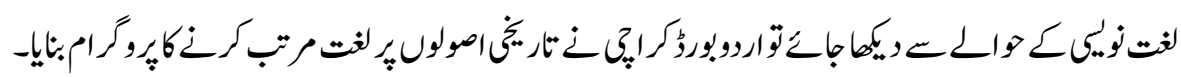

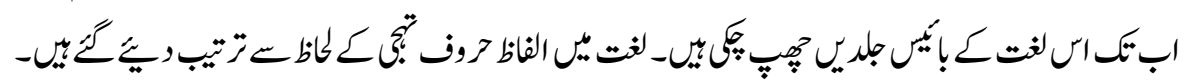

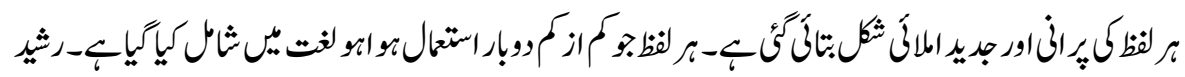

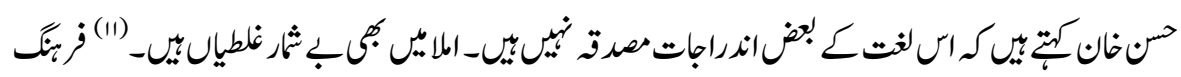

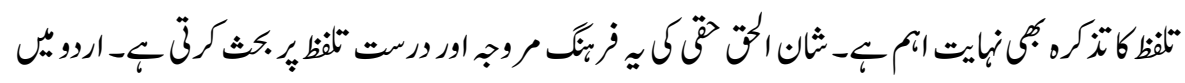

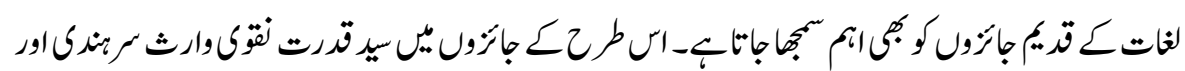

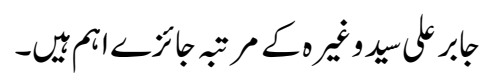

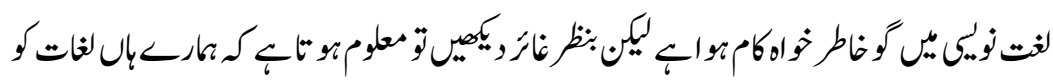

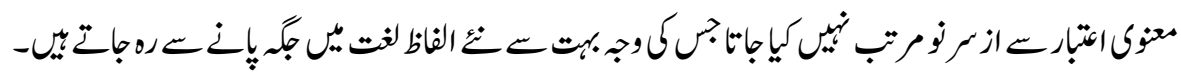

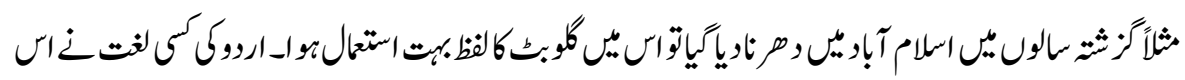

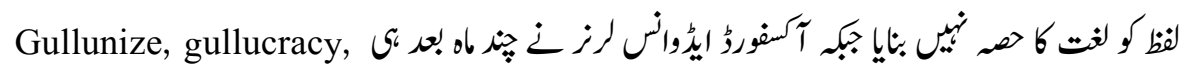

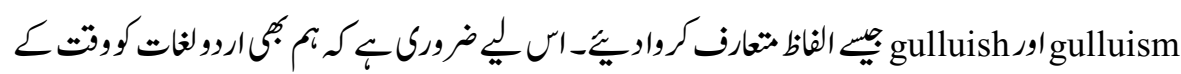

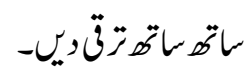




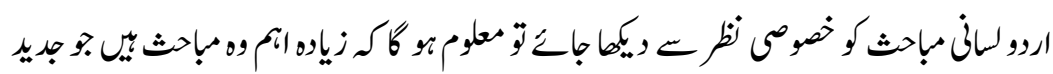

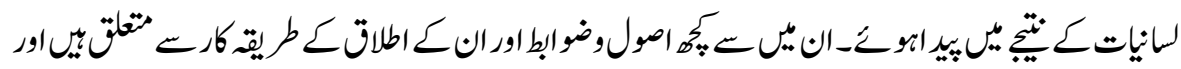

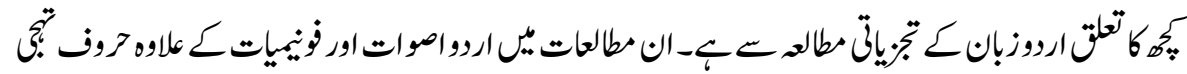

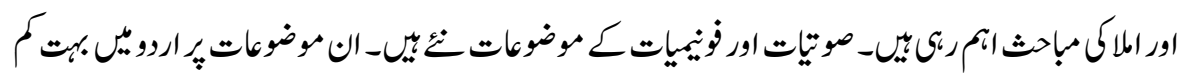

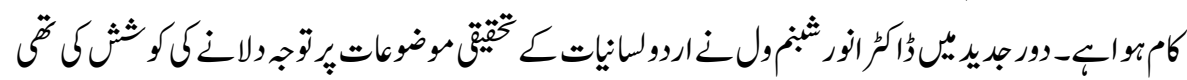

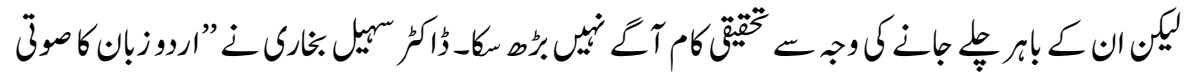

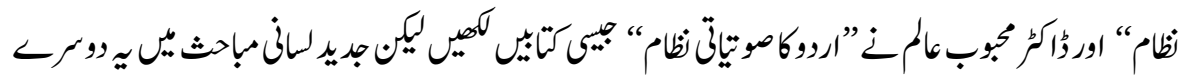

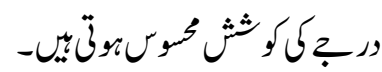

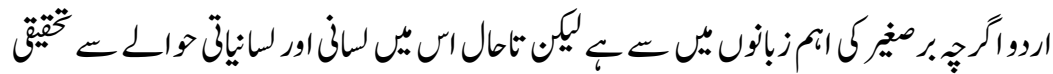

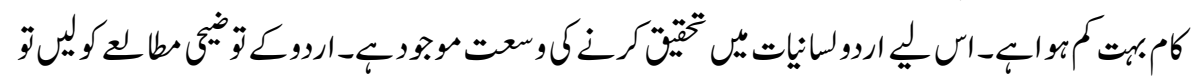

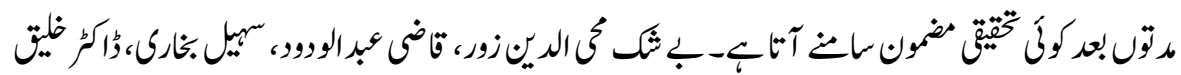

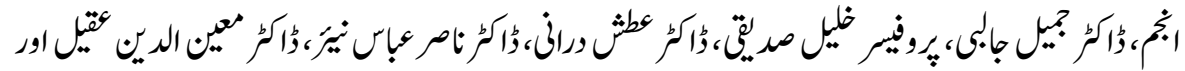

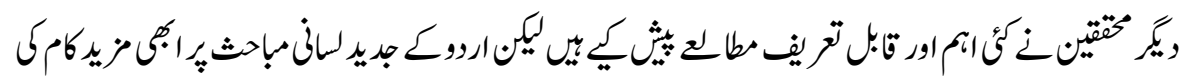
نروتب

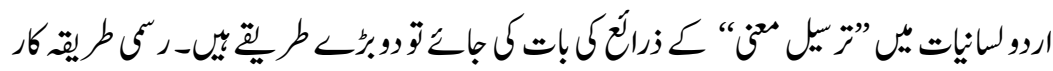

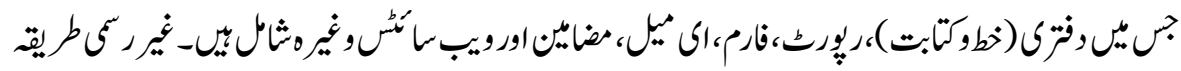

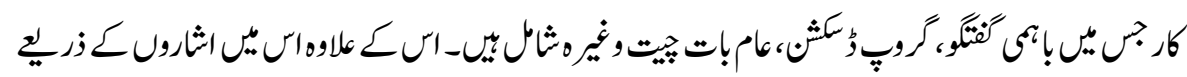

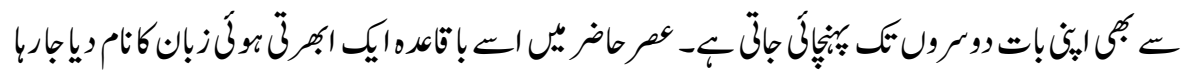

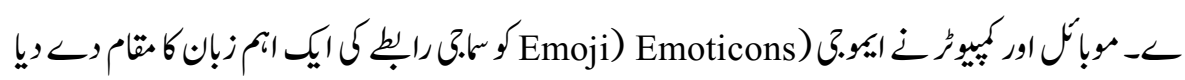

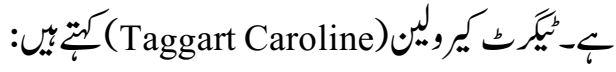

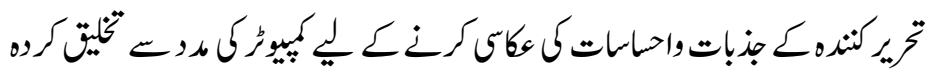

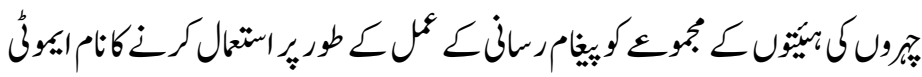
(11) $-{ }^{\prime}$ 


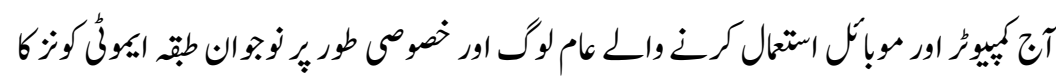

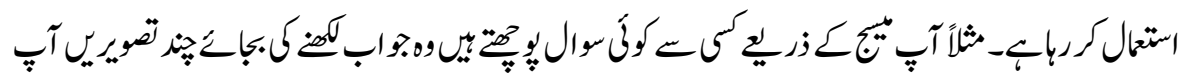

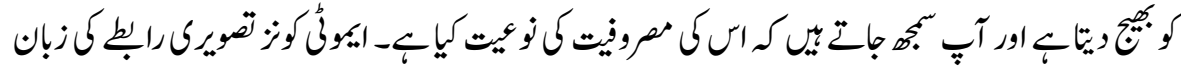

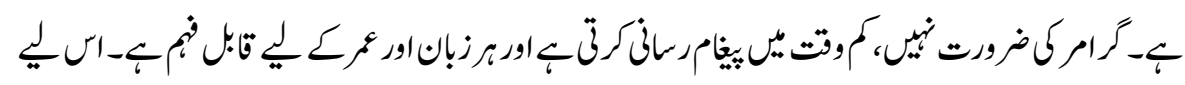

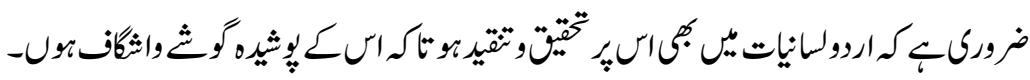

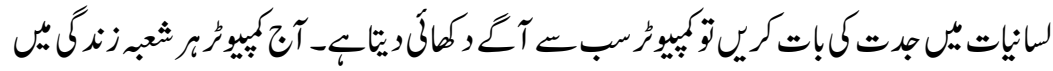

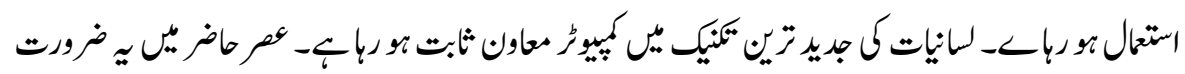

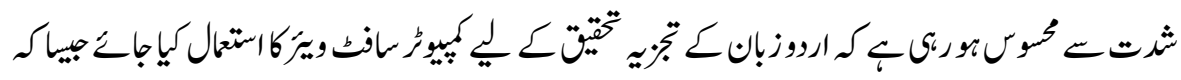

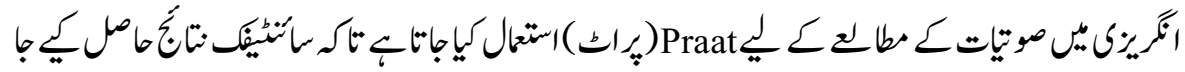

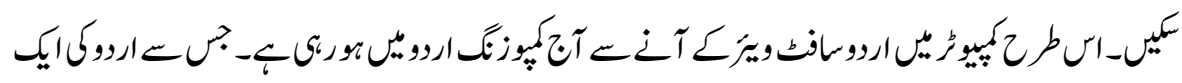

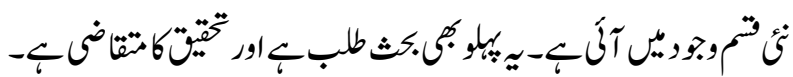

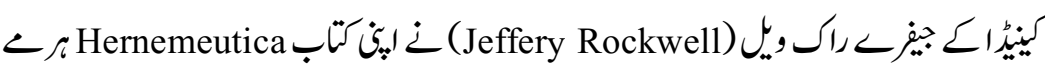

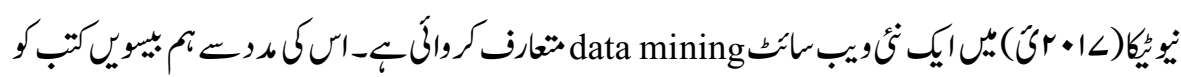

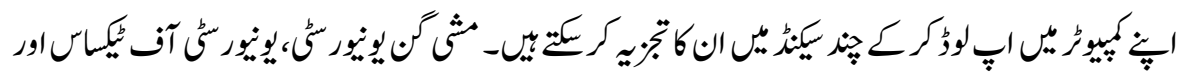

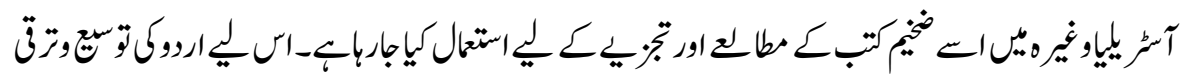

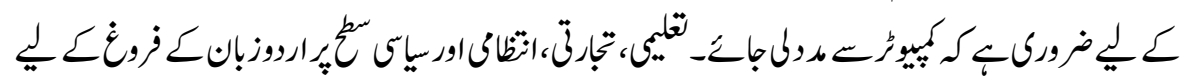

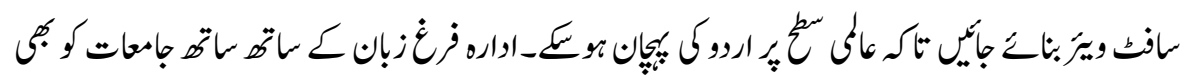

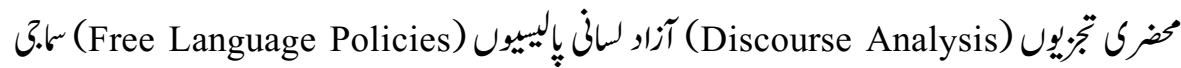

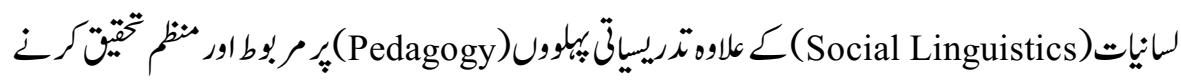

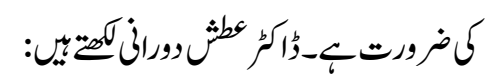

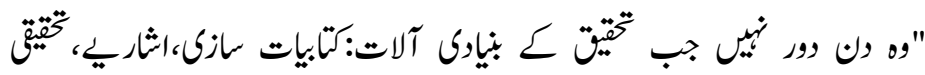

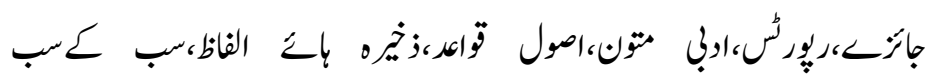

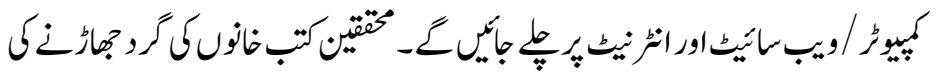




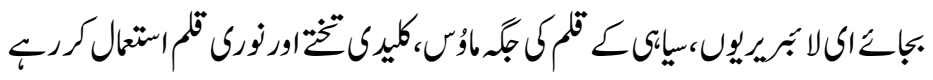

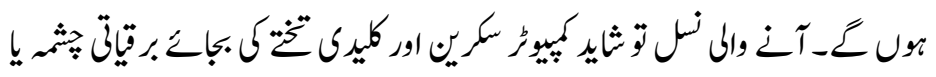

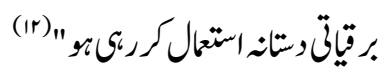

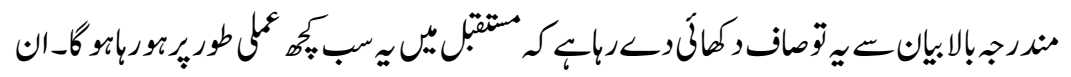

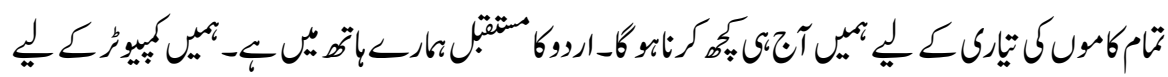

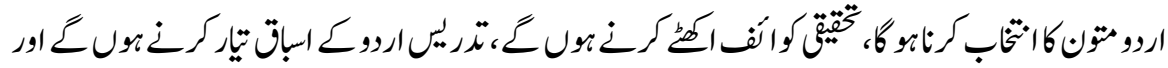

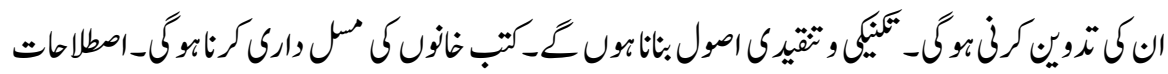

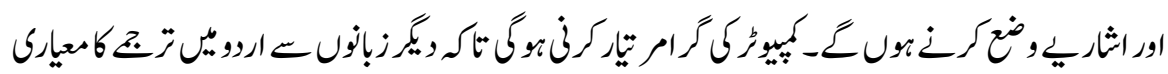

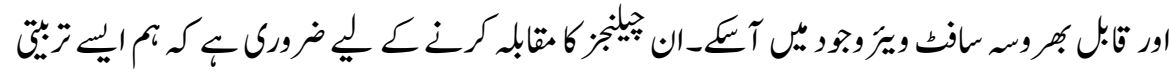

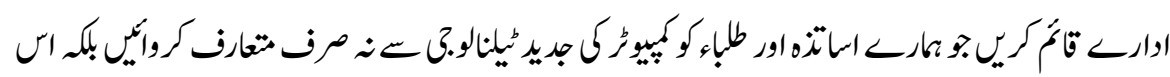

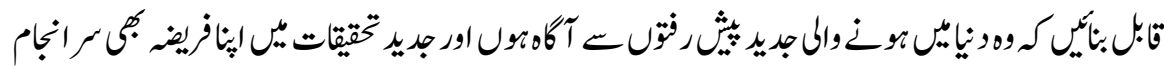

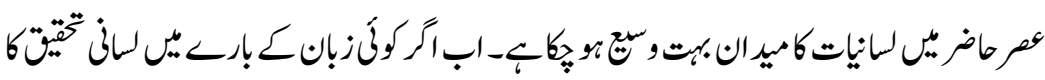

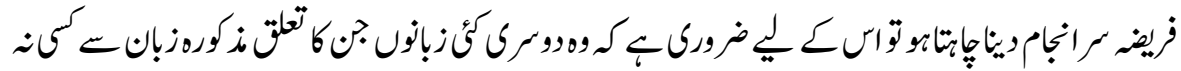

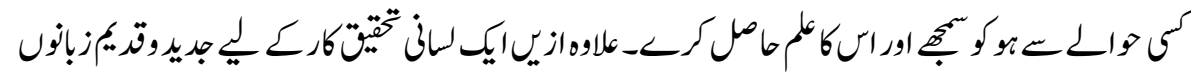

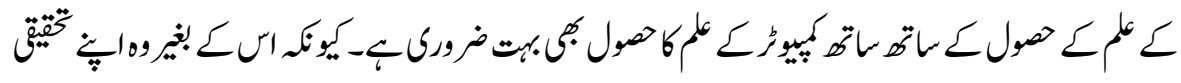

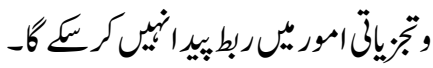




$$
\text { و والـجات }
$$

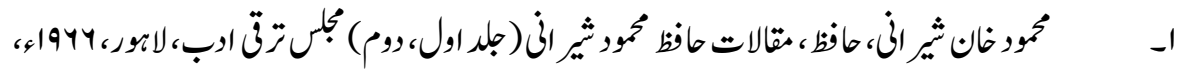

1040

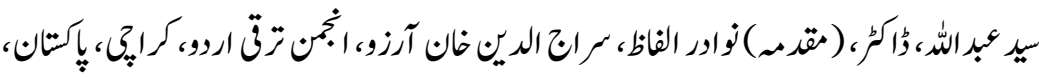

r.91901

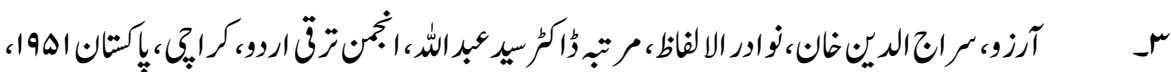

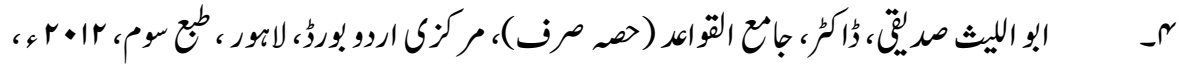

I

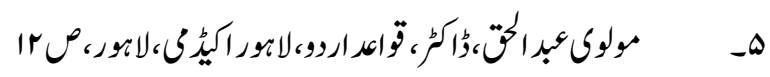

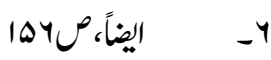

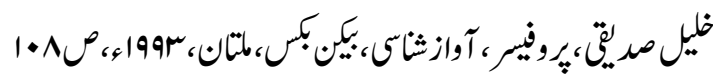

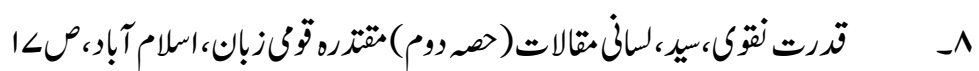

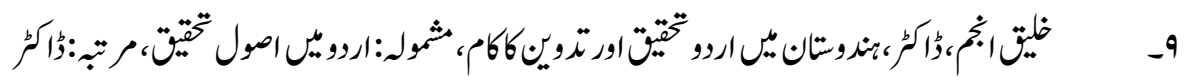

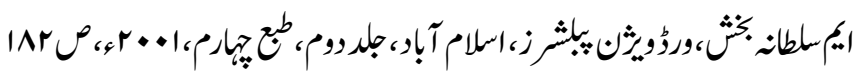

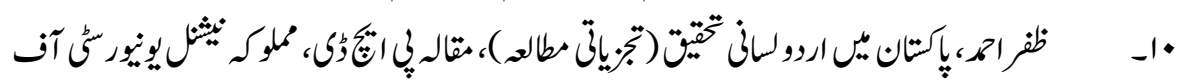

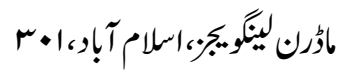

Taggart Caro Line, New Words for old recycling on language for the

.modern world, Macheal of Mara Books Via Google Books, 25th Oct

\section{$r+1 /$}

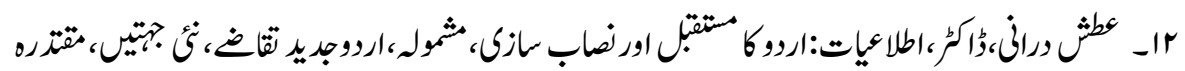

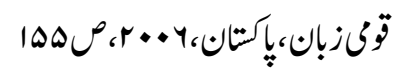

